\title{
The Role of Factor XI in Thrombin Generation Induced by Low Concentrations of Tissue Factor
}

\author{
Irene M. L. W. Keularts ${ }^{1}$, Ariella Zvelin², Uri Seligsohn ${ }^{3}$, H. Coenraad Hemker ${ }^{1}$, \\ Suzette Béguin ${ }^{1}$
}

\author{
${ }^{1}$ Department of Biochemistry, University of Maastric ht, Maastric ht, The Netherlands; \\ ${ }^{2}$ Institute of Thrombosis and Hemostasis, Department of Hema tology, Chaim Sheba Medic al Center, Tel-Hashomer \\ and Sackler School of Medic ine, Tel-Aviv University, Israel
}

\section{Key words}

Factor XI, thrombin generation, platelet procoagulant activity, tissue factor

\section{Summary}

Thrombin generation has been studied in the plasma of severely factor XI deficient patients under conditions in which contact activation did not play a role. In platelet-rich as well as platelet-poor plasma, thrombin generation was dependent upon the presence of factor XI at tissue factor concentrations of between 1 and $20 \mathrm{pg} / \mathrm{ml}$ i.e. 0.01 to $0.20 \%$ of the concentration normally present in the thromboplastin time determination. The requirement for factor $\mathrm{XI}$ is low; significant thrombin generation was seen at $1 \%$ factor XI; at $10 \%$, thrombin formation was nearly normalised. A suspension of normal platelets in severely factor XI deficient plasma did not increase thrombin generation. This implies that there is no significant factor XI activity carried by normal platelets, although the presence of factor XI and factor XI inhibitors in platelets cannot be ruled out.

\section{Introduction}

The precise role of factor XI (FXI) in physiological coagulation is still a matter of debate. In the contact phase of the intrinsic pathway of coagulation, FXI is activated by factor XIIa in the presence of high molecular weight kininogen (HK) and a negatively charged surface (1-5). Factor XIa then activates factor IX, that, together with factor VIIIa on phospholipid surfaces, constitutes the intrinsic factor $\mathrm{X}$ activating complex (6). The observation that factor XII (FXII) deficiency does not cause a hemorrhagic disease casts doubt on the importance of contact activation for physiological blood coagulation (7) whereas the discovery of the "Josso loop" i.e. the activation of factor IX (FIX) by tissue factor (TF) and factor VIIa (8-10) assigned a role to the antihaemophilia A and B factors independent of contact activation.

Unlike FXII deficiency, FXI deficiency causes an injury-related bleeding tendency (11-13), a fact that is not explained by the classical

Correspondence to: Dr. S. Béguin, Synapse bv., CARIM, University of Maastricht, P.O. Box 616, 6200 MD Maastricht, The Netherlands - Tel.: +3143-3881674; Fax: +31-43-3670988; E-mail: s.beguin@thrombin.com contact activation mechanism nor by the "Josso loop". When it was found that FXI can be activated by trace amounts of thrombin $(14,15)$ it was surmised that it might serve in a feedback-loop involving thrombin $\rightarrow$ FXI $(a) \rightarrow F I X(a) \rightarrow F X(a) \rightarrow($ pro $)$ thrombin $[\rightarrow$ indicates activation of the zymogen (right of the arrow) by the enzyme (left of the arrow)], that sustains the tissue-factor-dependent (extrinsic) pathway. In addition, it was recently observed that FXI is required for the generation of lysis-resistant clots (16). It was inferred from these experiments that the presence of FXI increases the generation of the thrombin activatable fibrinolysis inhibitor (TAFI) at low concentrations of TF (17). This was confirmed by Cawthern et al. (18) who showed that in FXI deficient plasma, at low TF concentrations, several thrombin products (factor $\mathrm{V}$ activation products, fibrinopeptide $\mathrm{A}$, thrombin-antithrombin complexes, osteonectin release from platelets) are formed slower than in normal plasma. However, in these experiments thrombin generation was not measured directly. The literature thus suggests that thrombin generation is quantitatively dependent upon the combined concentration of TF and FXI. To further explore this relationship, we directly measured in the present study thrombin generation in severe and less severe inherited FXI deficiency, both in platelet-rich plasma (PRP) and platelet-poor plasma (PPP).

\section{Materials and Methods}

Chemicals

Apyrase and bovine serum albumin (BSA) were purchased from Sigma (St. Louis, MO, USA). The chromogenic substrate used for thrombin determination was S2238 (H-D-Phe-Pip-Arg-pNA.2HC1). Calcium- and polybrenefree recombinant relipidated TF (rTF) was a gift from Dade (Düdingen, Switzerland). Staphylocoagulase was prepared as described earlier (19). The phospholipid vesicles used consist of 20 mole-\% phosphatidyl serine (PS) and 80 mole- $\%$ phosphatidyl choline (PC) and were prepared as previously described (20). Bovine purified factors Va, Xa and human prothrombin were kindly provided by Dr. R Wagenvoord (Synapse bv., University Maastricht, The Netherlands). The antibody used for blocking FXII in plasma, MoAb OT2 (21) was a gift from Prof. Dr. E. Hack (CLB Amsterdam, The Netherlands). Kaolin was "Kaolin léger" provided by B.L.B. Laboratoires du Bois de Boulogne (Puteaux-France).

\section{Buffers/Solutions}

Buffer A consists of $20 \mathrm{mM}$ hepes, $150 \mathrm{mM} \mathrm{NaCl}, 0.5 \mathrm{~g} / \mathrm{l}$ bovine serum albumin (BSA), pH 7.35. Buffer B is buffer A with $20 \mathrm{mM}$ EDTA adjusted at $\mathrm{pH}$ 7.9. Acid citrate dextrose (ACD) consists of $80 \mathrm{mM}$ tri-sodium citrate, $52 \mathrm{mM}$ citric acid and $183 \mathrm{mM}$ glucose. 
Table 1 Variation in parameters associated with the thrombogram

\begin{tabular}{|c|c|c|c|c|}
\hline Plasma & $\begin{array}{l}\text { Lag-phase } \\
\text { (min) }\end{array}$ & $\begin{array}{l}\text { ETP } \\
\text { PRP } \\
\text { (nM.min) }\end{array}$ & $\begin{array}{l}\text { Peak } \\
(\mathrm{nM})\end{array}$ & $\begin{array}{l}\text { PT (PRP) } \\
\text { consumed } \\
(\%)\end{array}$ \\
\hline Normal (20) & $6 \pm 1$ & $532 \pm 37$ & $116 \pm 14$ & $94.8 \pm 14.8$ \\
\hline FXI type II (6) & $11.3 \pm 1.2$ & $159 \pm 27$ & $15.6 \pm 2$ & $57.2 \pm 9.2$ \\
\hline FXI type III (3) & 6.5 & 336 & 82 & n.d. \\
\hline
\end{tabular}

Data are presented as mean $\pm \mathrm{SD}$, PT is prothrombin

\section{Blood and Plasma}

Blood was obtained through antecubital venapuncture from apparently healthy individuals who consented to participate in this study. Platelet rich plasma (PRP) was prepared by centrifugation of freshly drawn blood (1 volume tri-sodium citrate $0.13 \mathrm{M}$ to 9 volumes blood) at $265 \mathrm{~g}, 10 \mathrm{~min}$ at $25^{\circ} \mathrm{C}$. The platelets were counted and the PRP was adjusted to $300 \times 10^{9} / \mathrm{L}$ with autologous PPP. Platelet poor plasma (PPP) was made by double centrifugation at $2900 \mathrm{~g}, 10 \mathrm{~min}$ at $25^{\circ} \mathrm{C}$. Experiments were always started within $1 \mathrm{~h}$ after venapuncture.

FXI deficient plasmas were obtained from individuals whose genotype had been previously determined (22). They presented with either a nonsense mutation (type II) or a missence mutation (type III). The severity of FXI deficiency is linked to the genotype. Homozygotes for the type II mutation have a FXI level of $1.2 \pm 0.5 \%$ whereas homozygotes for the type III mutation have a plasma level of $9.7 \pm 3.8 \%$ (22). Since even minute amounts of FXI suffice for stabilizing clots (16), we used the severe deficiency plasmas for type II homozygotes, unless indicated otherwise.

Factor VII-deficient plasmas were a gift from Dr. S. Belluci (Hôpital Lariboisière, Paris, France). TFPI (tissue factor pathway inhibitor)-depleted plasma was a gift from Dr. Theo Lindhout (University Maastricht, The Netherlands).

Reconstituted PRP was prepared by suspending normal washed platelets in pre-warmed PPP $\left(37^{\circ} \mathrm{C}\right)$ to a concentration of $300 \times 10^{9} / \mathrm{L}$. Washed platelets were obtained from ACD blood (1 volume ACD to 5 volumes of blood). Platelets were sedimented by centrifugation for $2 \mathrm{~min}$ at $2000 \mathrm{~g}$ in the presence of apyrase (0.2 U ADPase/ml) and washed as described before (23).

\section{Thrombin Generation Test in PRP}

In order to minimize FXI (FXI) activation via the contact activation path-way, we used hydrophobic material (polypropylene tubes and pipettes) throughout. PRP $(480 \mu \mathrm{l})$ was incubated with $120 \mu \mathrm{l}$ buffer $\mathrm{A}$ at $37^{\circ} \mathrm{C}$ and the mixture was gently stirred with a spatula. After $5 \mathrm{~min}$, coagulation was initiated with $120 \mu \mathrm{l}$ of $0.1 \mathrm{M} \mathrm{CaCl}_{2}$ containing rTF to a final concentration of $7.5 \mathrm{pg} / \mathrm{ml}$ (unless indicated otherwise in the figures). At $30 \mathrm{~s}$ or 1 min intervals after triggering, $10 \mu \mathrm{l}$ was removed from the reaction mixture and introduced into prewarmed cuvettes containing $490 \mu \mathrm{l}$ of buffer B with $200 \mu \mathrm{M}$ S2238 in order to measure thrombin. As soon as the plasma coagulated, the clot was wound on a small plastic spatula and removed, without interrupting the sampling rhythm. After about $2 \mathrm{~min}$, the reaction in the cuvettes containing the subsamples was stopped with $300 \mu \mathrm{l}$ of $1 \mathrm{M}$ citric acid. Sampling and stopping times were recorded by a computer. Optical densities were measured with a spectrophotometer at $405 \mathrm{~nm}$. From the OD, the recorded reaction time and the calibration factor $(1 \mathrm{OD} / \mathrm{min}=725 \mathrm{nM}$ thrombin $)$, the amidolytic activity in the samples was calculated. The time-course of thrombin was obtained from the amidolytic activity data as described earlier (24). Control experiments showed that the removal of the clot did not significantly change the thrombin generation curve even though addition of normal plasma clots at zero time does enhance thrombin generation. Results to be published indicate that this is due to (a) activation of platelets by fibrin (b) the role of adsorbed thrombin and (c) the role of FXI carried by normal plasma clots (manuscripts in preparation). Residual sera were kept on ice and centrifuged at high speed for 1 min to remove remaining cells and debris; then they were stored at $-80^{\circ} \mathrm{C}$ for later analysis of residual prothrombin. Up to six curves could be run simultaneously and only simultaneous curves were compared in the experiments. Table 1 shows the variation of some of the features of the thrombogram.

\section{Intrinsic Thrombin Generation in PPP}

In plastic tubes, under continuous agitation at $37^{\circ} \mathrm{C}, 240 \mu \mathrm{l}$ of PPP was incubated with $40 \mu \mathrm{l}$ of buffer A in which $0.25 \mathrm{mg} / \mathrm{ml}$ kaolin was suspended. After $4 \mathrm{~min}, 20 \mu \mathrm{l}$ of $180 \mu \mathrm{M} 20$ mole-\%/80 mole- $\%$ phosphatidylserine (PS)/phosphatidylcholine (PC) (final concentration in the total reaction mixture: $10 \mu \mathrm{M}$ PS/PC) was added. Thrombin generation was triggered 5 min after the start of the incubation with $60 \mu \mathrm{l}$ of $0.1 \mathrm{M}$ of $\mathrm{CaCl}_{2}$ and thrombin generation was measured according to the above-described procedure.

\section{Extrinsic Thrombin Generation in PPP}

$240 \mu \mathrm{l}$ of PPP was incubated for 5 min with $40 \mu \mathrm{l}$ of buffer A, and $20 \mu \mathrm{l}$ of $\mathrm{PS} / \mathrm{PC}$ solution so as to obtain final concentration of $10 \mu \mathrm{M}$. Thrombin generation was triggered with $60 \mu \mathrm{l}$ of $0.1 \mathrm{M} \mathrm{CaCl}_{2}$ containing rTF at the concentrations indicated and thrombin generation was measured as above described.

\section{Measurement of Residual Prothrombin in Serum}

In the serum left after thrombin generation is over, we determined the concentration of residual prothrombin at a zero level of free thrombin. Staphylocoagulase complexes with prothrombin in a stoichiometric staphylocoagulaseprothrombin complex, which has the same specific activity towards small molecular weight substrates as thrombin $(19,25)$. The sample (10 $\mu$ l of either PPP diluted 1:20-1:100 or serum diluted 1:4 in hepes buffer A) was incubated with $465 \mu \mathrm{l}$ buffer B containing staphylocoagulase $(0.22 \mu \mathrm{M})$. After 10 min incubation, $25 \mu \mathrm{l}$ of $4 \mathrm{mM} \mathrm{S} 2238$ was added and the amidolytic activity measured. For the serum, the spontaneous activity due to $\alpha_{2} \mathrm{M}$-thrombin is substracted from the activity obtained in the presence of staphylocoagulase. The amount of prothrombin consumed is obtained by dividing the residual prothrombin in serum by the total prothrombin measured in PPP.

\section{Results}

\section{FXI Is Required for Thrombin Generation at Low Tissue Factor Concentration}

As could be expected from the observations on clot lysis (16), the role of FXI in thrombin generation, in the absence of contact activation, is only obvious at low TF concentrations. The difference between FXI deficient plasma and normal plasma is most clearly seen at 7-10 pg/ml of TF (Figs. 1 and 2). For comparison: the final concentration in a thromboplastin time determination is $\sim 10 \mathrm{ng} / \mathrm{ml}$. At TF concentrations of $1 \mathrm{pg} / \mathrm{ml}$ and lower, the amount of thrombin that was generated in normal plasma and FXI deficient plasma alike did not rise above $5 \mathrm{nM}$. To ensure the virtual absence of contact activation, similar experiments 


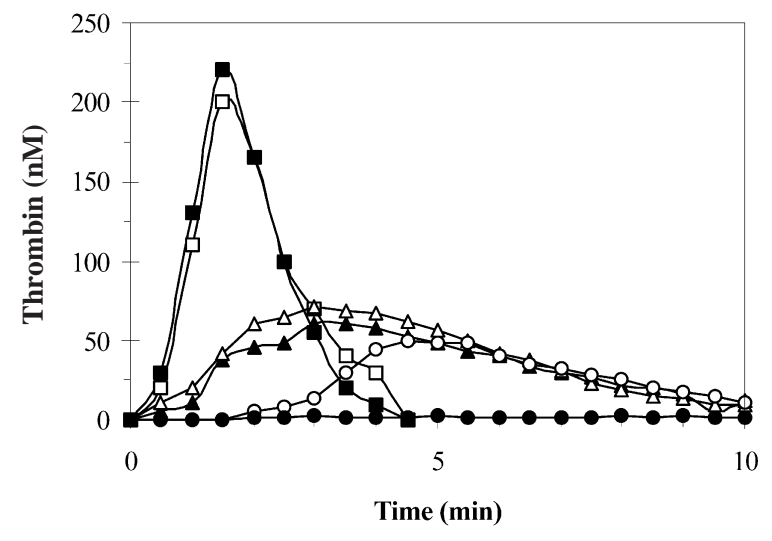

Fig. 1 Dependency of thrombin formation on tissue factor concentration in control plasma and FXI deficient PPP. Plasma was supplemented with $10 \mu \mathrm{M}$ $\mathrm{PS} / \mathrm{PC}$ and thrombin generation was triggered with varying concentrations of tissue factor: $300(\square) ; 37.5(\triangle)$ and $7.5(\bigcirc) \mathrm{pg} / \mathrm{ml}$ (final concentration). Open symbols: control plasma, closed symbols: FXI deficient plasma

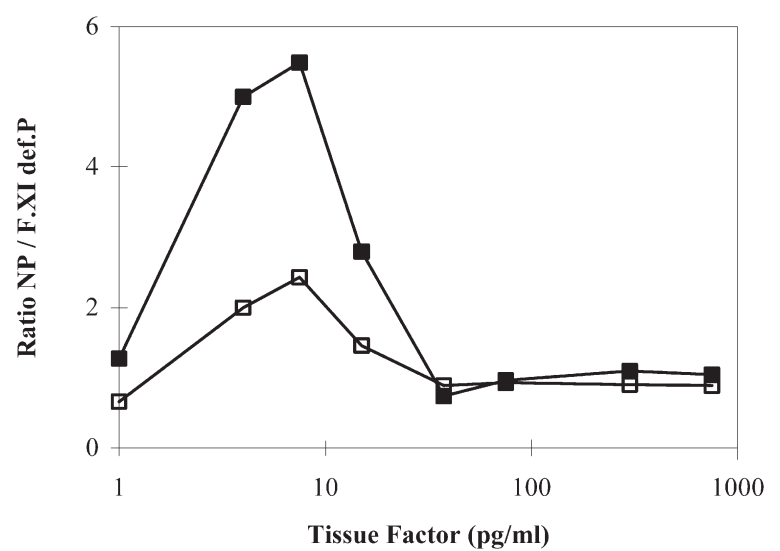

Fig. 2 Dependency of thrombin generation on tissue factor concentration. 口: maximal rate of thrombin generation (as observed in thrombin generation curves in Fig. 1), $\square$ : peak value of thrombin generation. The effect was expressed as ratio of the value in normal plasma over that in factor XI deficient plasma

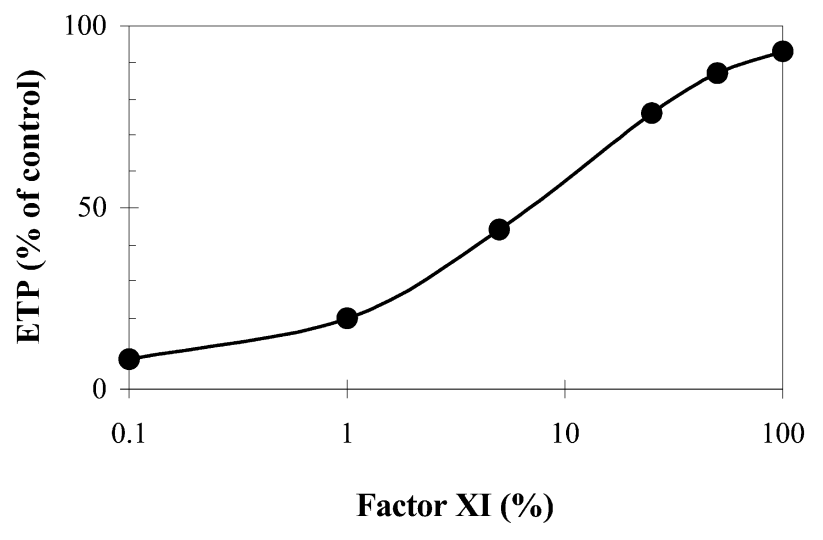

Fig. 4 Relation between factor XI concentration and ETP in PPP. Factor XI deficient plasma is arbitrarily set at $0.1 \% \mathrm{FXI}$ on the $\mathrm{X}$-axis. By mixing control plasma with factor XI deficient plasma, different concentrations of FXI were obtained. The ETP values were determined as the area under the thrombin generation curve. Absolute values: normal plasma $263 \pm 23 \mathrm{nM} / \mathrm{min}(\mathrm{n}=20)$, FXI type II deficient plasma $21.9 \pm 5 \mathrm{nM} / \mathrm{min}(\mathrm{n}=6)$, FXI type III deficient plasma $135 \pm 25 \mathrm{nM} / \mathrm{min}(\mathrm{n}=3)$

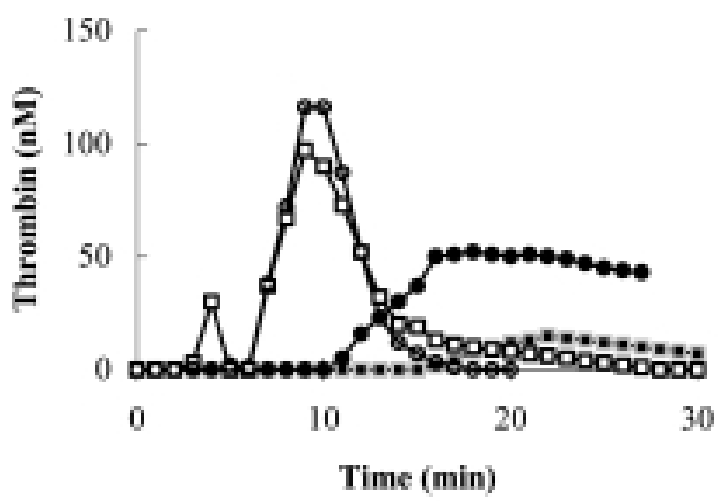

Fig. 5 Thrombin generation in PRP of a FXI deficient patient. $\mathbf{\square}$ : FXI deficiency; $\bigcirc$ : normal control; $\bigcirc$ : FXI deficiency, $1 \%$ normal plasma added; $\square$ : FXI deficiency, $10 \%$ normal plasma added. $7.5 \mathrm{pg} / \mathrm{ml} \mathrm{rTF}$ was present throughout

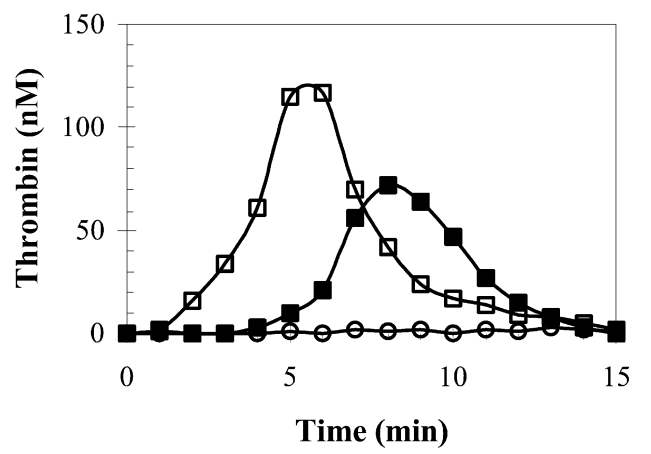

Fig. 3 Thrombin generation, dependency on TF-factor VII interaction. Control (normal plasma), $\square$ : TFPI-depleted plasma, $\bigcirc$ : FVII deficient plasma. Tissue factor concentration was $7.5 \mathrm{pg} / \mathrm{ml}$

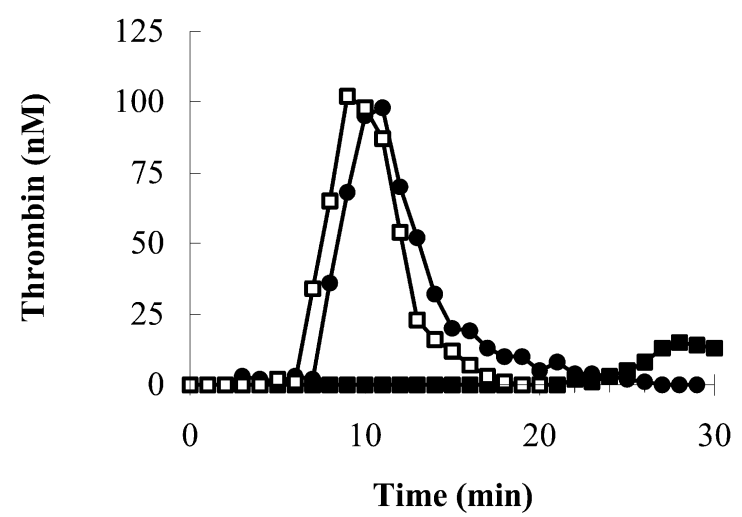

Fig. 6 Thrombin generation in PRP of a FXII deficient patient. $\square$ : Normal plasma with $7.5 \mathrm{pg} / \mathrm{ml}$ rTF; $\mathbf{\square}$ : FXII deficiency, no rTF; : FXII deficiency, $7.5 \mathrm{pg} / \mathrm{ml} \mathrm{rTF}$ 


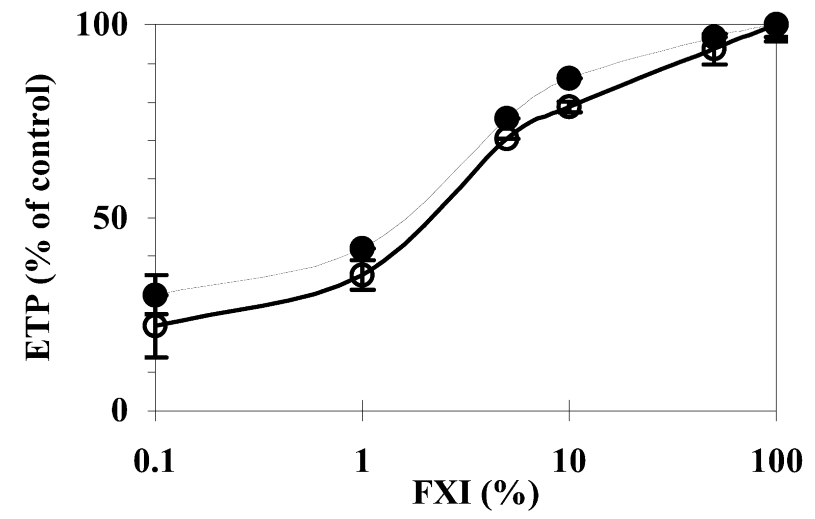

Fig. 7 Relation between factor XI concentration and ETP in PRP; effect of normal platelets. Autologous platelets (experiments in duplo); $\bigcirc$ normal platelets. $7.5 \mathrm{pg} / \mathrm{ml} \mathrm{rTF}$ was added. See further legend to Fig. 4

Table 2 The effect of washed normal platelets on prothrombin consumption in factor XI deficiency

\begin{tabular}{llll}
\hline Plasma & Platelets & N & $\begin{array}{l}\text { Prothrombin consumed } \\
(\%)\end{array}$ \\
\hline Control (NP) & Normal & 12 & $94.8 \pm 1.8$ \\
FXI def. Plus 10\% NP & FXI type II & 2 & 92.8 \\
FXI deficient & Normal & 8 & $59.4 \pm 7.4$ \\
FXI deficient & FXI type II & 8 & $58.6 \pm 7$ \\
\hline
\end{tabular}

$\mathrm{NP}=$ normal pool

Residual prothrombin was measured in the serum after generation of free thrombin stopped for at least 10 min. Normal platelets were suspended in FXI deficient and normal plasma.

were carried out in the presence of an inhibitory antibody against FXII (21). Identical graphs were obtained whether or not the MoAb against FXII was added (results not shown).

In order to check whether thrombin generation was completely dependent upon the TF pathway, we repeated the experiments in inherited factor VII deficient PPP and in plasma from which TF pathway inhibitor was removed by immuno-depletion. Fig. 3 shows that the dependence upon factor VII was complete whereas the absence of TFPI caused a significant enhancement of thrombin generation. While in contact activation (triggered with kaolin), both FVII deficient and TFPI depleted PPP, but not FXII-depleted PPP, showed normal thrombin generation (results not shown). These experiments indicate that, under our experimental conditions, the contribution of the intrinsic pathway to thrombin formation is negligible whereas the contribution of the TF-dependent pathway is profound.

At a fixed low TF concentration $(7.5 \mathrm{pg} / \mathrm{ml})$, the area under the thrombin generation curve (endogenous thrombin potential, ETP) was dependent upon the level of FXI. Fig. 4 illustrates that in the presence of very low concentrations of FXI $(<1 \%)$ only few thrombin was generated. In contrast, a concentration of $\sim 10 \%$ was sufficient to obtain $>50 \%$ of the ETP. In type III patients, the ETP was $51 \%$ of normal $(n=3)$ The maximum rate and peak values of thrombin formation as well as prothrombin consumption varied proportionally with the ETP in FXI deficient plasma (data not shown).

\section{FXI Dependency of Thrombin Generation in Platelet-rich Plasma}

In the presence of trace amounts of TF, thrombin generation in PRP from a patient with severe FXI deficiency was severely impaired (Fig. 5). In five additional type II patients (Table 1), thrombin generation was markedly impaired as judged from the lag-phase length, ETP and maximal peak values as well as the amount of prothrombin consumed. Adding $1 \%$ normal PPP normalized it. In three type III patients with a residual FXI level of $\sim 9 \%$ thrombin generation was not significantly different from normal (Table 1). In PRP of FXII deficient patient, however, thrombin generation was absent when TF was omitted and normalized in the presence of a low TF concentration (Fig. 6). This indicates that, in PRP like in PPP, FXI contributed to thrombin generation via the TF.

In order to investigate whether normal platelets carry FXI activity, we studied the effect of suspending normal platelets in FXI deficient plasma. Initially, we showed that thrombin generation and prothrombin consumption were similar in normal PRP and PPP to which we added normal washed platelets. Addition of normal washed platelets to FXI deficient plasmas did not augment the deranged thrombin generation and prothrombin consumption (Fig. 7 and Table 2). This indicates that platelets from normal donors do not carry any additional FXI activity.

\section{Disc ussion}

Physiological coagulation is probably triggered by suboptimal TF concentrations. Josso (8) was the first to recognise that at low TF concentrations FIX is activated by the FVII-TF complex. This "Josso" pathway was later independently rediscovered by others $(9,10)$. This mechanism accounts for a role of the anti-hemophilic factors (FVIII and FIX) in TF-dependent thrombin generation and provides an explanation for the fact that FXII-deficiency does not cause a haemorrhagic tendency whereas the haemophilias do. It has been puzzling, however, that FXI deficient patients manifest excessive bleeding, particularly following injury of tissues exhibiting activation of the fibrinolytic system like oral and nose mucosa and urinary tract. The Josso pathway did not account for this observation. The solution of the puzzle was suggested by the discovery that thrombin can activate FXI $(14,15)$. This could explain why patients with FXI deficiency may bleed and patients with FXII deficiency do not. It was later shown that at low TF and FXI concentrations, clots did form but had a tendency to lyse readily (16). From these observations, it has been inferred that thrombin activation of FXI serves as an amplification loop that enhances further thrombin generation. In the absence of FXI, less thrombin would be generated, and hence less thrombin products, such as activated TAFI, factor Va etc, would appear (16-18). In this study we tested this hypothesis by directly measuring the effect on thrombin generation of varying concentrations of FXI and TF.

FXI was indeed shown to be essential for normal thrombin generation at low TF concentrations (Figs. 1 and 2). Only minute amounts (1-5\%) of FXI were required to obtain half normal thrombin generation. Under our experimental conditions thrombin generation was totally dependent on the TF pathway and unrelated to possible contact activation of FXII. Thrombin generation was abolished in the absence of factor VII, significantly enhanced when TFPI was neutralized and it remained unchanged in the presence of MoAb against FXII.

The requirement of FXI for normal thrombin generation was especially obvious in the presence of platelets in the clinically interesting range of 1-10\% FXI levels (Figs. 5, 7). In the absence of added TF, thrombin generation was low in both FXI and FXII deficient plasmas. 
When a small amount of rTF was added, thrombin generation in FXIdeficiency remained low, while in FXII deficient plasma, it normalized (Figs. 6, 7). In the presence of platelets, the lag-time of thrombin formation was longer than when phospholipids $(10 \mu \mathrm{M})$ were added to provide a procoagulant surface, indicating that platelet membrane scrambling via the first trace amounts of thrombin formed is the rate limiting step under these conditions.

Taken together, these data indicate that FXI is required for thrombin generation in both PPP and PRP when initiated by low concentrations of TF. Conceivably, the amount of factor IXa produced by low concentrations of TF and factor VIIa is insufficient and needs to be reinforced by further activation of FIX by FXIa generated via thrombin activation.

Platelet factor FXI was suggested to play a role in hemostasis and was implicated as a possible explanation for the lack of bleeding manifestations in some patients with severe FXI deficiency (26). In contrast, Schiffman et al. (27) demonstrated that platelet FXI had a negligible contribution to coagulation. FXIa inhibitory activity (28) has been characterized by identification of two inhibitors: protease nexin II (29-31), a $120 \mathrm{kD}$ Kunitz-type serine protease inhibitor and PIXI, a $8.5 \mathrm{kD}$ non competitive inhibitor of FXIa-catalyzed-FIX activation (32). In our study, we addressed the question whether normal platelets would indeed contribute to thrombin generation in the milieu of severe FXI deficient plasma. As can be seen from Fig. 7 and Table 2, we were unable to demonstrate any activity of FXI provided by normal platelets added to FXI deficient plasma. Moreover, impaired thrombin generation due to the absence of FXI was of the same order of magnitude in PPP and in PRP. Thus, we could find no evidence for FXI-like activity in platelets. We cannot exclude the possibility that FXI activity was washed off the normal platelets or that the effect of the platelet inhibitors of FXIa supervened. Activated platelets may also boost FXI activation by thrombin (33). However, in our experiments, this phenomenon was not rate limiting.

In summary, direct measurement of thrombin generation showed that FXI is required for normal thrombin generation when triggered by low amounts of TF. The concentrations of FXI that are required are very low, which correlates with the clinical observation that patients who are homozygotes for the type II mutation and have FXI levels of $\sim 1 \%$ of normal bleed more seriously than patients who are homozygotes for type III mutations (FXI levels $\sim 9 \%$ of normal) (22). This strongly suggests a correlation between thrombin generation and clinical bleeding. Platelets were found not to contribute any FXI activity under these conditions.

\section{Acknowledgement}

This study was supported by a Program Grant 900-26-192 from the Dutch Organization for Scientific Reseach (NWO).

\section{References}

1. Movat HZ, Ozge-Anwar AH. The contact phase of blood coagulation: Clotting factors XI and XII, their isolation and interaction. J Lab Clin Med 1974; 84: 861-78.

2. Heck LW, Kaplan AP. Substrates of Hageman factor. I. Isolation and characterization of human factor XI (PTA) and inhibition of the activated enzyme by alpha 1-antitrypsin. J Exp Med 1974; 140 (6): 1615-30.

3. Kurachi K, Davie EW. Activation of human factor XI (plasma thromboplastin antecedent) by factor XIIa (activated Hageman factor). Biochemistry 1977; 16 (26): 5831-9.
4. Bouma BN, Griffin JH. Human blood coagulation factor XI. Purification, properties, and mechanism of activation by activated factor XII. J Biol Chem 1977; 252 (18): 6432-7.

5. Thompson RE, Mandle R, Jr., Kaplan AP. Association of factor XI and high molecular weight kininogen in human plasma. J Clin Invest 1977; 60 (6): 1376-80.

6. Hemker HC, Esnouf MP, Hemker PW, Swart AC, Macfarlane RG. Formation of prothrombin converting activity. Nature 1967; 215 (98): 248-51.

7. Schmaier AH, Silverberg M, Kaplan AP, Colman RW. Contact activation and its abnormalities. In: Hemostasis and Thrombosis. Colman RW, Hirsh J, Marder VJ, Salzman EW, eds. Philadelphia: JB Lippincott Co., 1987; 18-38.

8. Josso F, Prou-Wartelle O. Interaction of tissue factor and factor VII at the earliest phase of coagulation. Thromb Diath Haemorr 1965; Suppl 17: $35-44$.

9. Osterud B, Rapaport SI. Activation of factor IX by the reaction product of tissue factor and factor VII: additional pathway for initiating blood coagulation. Proc Natl Acad Sci USA 1977; 74 (12): 5260-4.

10. Zur M, Nemerson Y. Kinetics of factor IX activation via the extrinsic pathway. Dependence of Km on tissue factor. J Biol Chem 1980; 255 (12): 5703-7.

11. Rapaport SI, Proctor RR, Patch MJ, Yettra M. The mode of inheritance of PTA deficiency: Evidence for the existence of major PTA deficiency and minor PTA deficiency. Blood 1961; 18: 149-165.

12. Bolton-Maggs PH, Young Wan-Yin B, McCraw AH, Slack J, Kernoff PB. Inheritance and bleeding in factor XI deficiency. Br J Haematol 1988; 69 (4): $521-8$

13. Seligsohn U. Factor XI deficiency. Thromb Haemost 1993; 70 (1): 68-71.

14. Naito K, Fujikawa K. Activation of human blood coagulation factor XI independent of factor XII. Factor XI is activated by thrombin and factor XIa in the presence of negatively charged surfaces. J Biol Chem 1991; 266 (12): 7353-8.

15. Gailani D, Broze GJ, Jr. Factor XI activation in a revised model of blood coagulation. Science 1991; 253 (5022): 909-12.

16. von dem Borne PA, Meijers JC, Bouma BN. Feedback activation of factor $\mathrm{XI}$ by thrombin in plasma results in additional formation of thrombin that protects fibrin clots from fibrinolysis. Blood 1995; 86 (8): 3035-42.

17. von dem Borne PA, Bajzar L, Meijers JC, Nesheim ME, Bouma BN. Thrombin-mediated activation of factor XI results in a thrombin-activatable fibrinolysis inhibitor-dependent inhibition of fibrinolysis. J Clin Invest 1997; 99 (10): 2323-7.

18. Cawthern, K, van 't Veer, C, Lock, JB, DiLorenzo, ME, Branda, RF, Mann, KG. Blood coagulation in hemophilia A and hemophilia C. Blood 1998; 91 (12): 4581-92.

19. Hendrix H, Lindhout T, Mertens K, Engels W, Hemker HC. Activation of human prothrombin by stoichiometric levels of staphylocoagulase. J Biol Chem 1983; 258 (6): 3637-44.

20. Rosing J, Tans G, Govers-Riemslag JW, Zwaal RF, Hemker HC. The role of phospholipids and factor $\mathrm{Va}$ in the prothrombinase complex. J Biol Chem 1980; 255 (1): 274-83.

21. Dors DM, Nuijens JH, Huijbregts CC, Hack CE. A novel sensitive assay for functional factor XII based on the generation of kallikrein-C1-inhibitor complexes in factor XII-deficient plasma by glass-bound factor XII. Thromb Haemost 1992; 67 (6): 644-8.

22. Asakai R, Chung DW, Davie EW, Seligsohn U. Factor XI deficiency in Ashkenazi Jews in Israel. N Engl J Med 1991; 325 (3): 153-8.

23. Heemskerk JW, Vis P, Feijge MA, Hoyland J, Mason WT, Sage SO. Roles of phospholipase $\mathrm{C}$ and $\mathrm{Ca}(2+)$-ATPase in calcium responses of single, fibrinogen-bound platelets. J Biol Chem 1993; 268 (1): 356-63.

24. Hemker HC, Willems GM, Beguin S. A computer assisted method to obtain the prothrombin activation velocity in whole plasma independent of thrombin decay processes. Thromb Haemost 1986; 56 (1): 9-17.

25. Kawabata S, Morita T, Iwanaga S, Igarashi H. Staphylocoagulasebinding region in human prothrombin. J Biochem (Tokyo) 1985; 97 (1): $325-31$. 
26. Walsh PN, Baglia FA, Jameson BA. Factor XI and platelets: activation and regulation. Thromb Haemost 1993; 70 (1): 75-9.

27. Schiffman S, Rimon A, Rapaport SI. Factor XI and platelets: Evidence that platelets contain only minimal factor XI activity and antigen. Br J Haematol 1977; 35: 429-36.

28. Soons H, Janssen-Claessen T, Hemker HC, Tans G. The effect of platelets in the activation of human blood coagulation factor IX by factor XIa. Blood 1986; 68 (1): 140-8.

29. Van Nostrand WE, Schmaier AH, Farrow JS, Cunningham DD. Protease nexin-II (amyloid beta-protein precursor): a platelet alpha-granule protein. Science 1990; 248 (4956): 745-8.

30. Bush AI, Martins RN, Rumble B, Moir R, Fuller S, Milward E, et al. The amyloid precursor protein of Alzheimer's disease is released by human platelets. J Biol Chem 1990; 265 (26): 15977-83.
31. Scott CF, Schapira M, James HL, Cohen AB, Colman RW. Inactivation of factor XIa by plasma protease inhibitors: predominant role of alpha 1-protease inhibitor and protective effect of high molecular weight kininogen. $\mathrm{J}$ Clin Invest 1982; 69 (4): 844-52.

32. Cronlund AL, Walsh PN. A low molecular weight platelet inhibitor of factor XIa: purification, characterization, and possible role in blood coagulation. Biochemistry 1992; 31 (6): 1685-94.

33. Oliver JA, Monroe DM, Roberts HR, Hoffman M. Thrombin activates factor XI on activated platelets in the absence of factor XII. Arterioscler Thromb Vasc Biol 1999; 19 (1): 170-7.

Received February 7, 2000 Accepted after revision February 6, 2001 